\title{
CUIDADO DE ENFERMAGEM: O SENTIDO PARA ENFERMEIROS E PACIENTES ${ }^{1}$
}

\author{
THE MEANING OF THE CONCEPT "NURSING CARE" FOR NURSES AND \\ PATIENTS \\ EL CUIDADO DE ENFERMERIA: SU SENTIDO PARA ENFERMEROSY \\ PACIENTES
}

\author{
Lúcia de Fátima da Silva ${ }^{2}$ \\ Marta Maria Coelho Damasceno ${ }^{3}$ \\ Carolina Maria de Lima Carvalho ${ }^{4}$ \\ Paula Daiane Silva de Souza ${ }^{4}$
}

\begin{abstract}
RESUMO: Pesquisa desenvolvida com o objetivo de compreender o conceito de cuidado de enfermagem a partir do discurso de enfermeiros e dos pacientes cujos cuidados thes são confiados. A coleta de dados realizou-se em janeiro de 2001, numa clinica médica de um hospital universitário, localizado em Fortaleza-CE. Para tanto, utilizou-se formulários para caracterizar as populaçōes amostrais, e entrevistas semi-estruturadas para obter os discursos. Os dados foram trabalhados descritivamente pela análise de discurso e, depois, submetidos à interpretação hermenêutica. Apreendeu-se que, para os profissionais, o cuidado de enfermagem prende-se à satisfaçāo das necessidades dos pacientes com vistas ao seu bem-estar fisico e emocional, entretanto, mesmo considerando o relacionamento interpessoal com os seres cuidados, eles se prendem à instância técnica. Já os pacientes aproximam o cuidado de enfermagem das manifestaçōes de atenção, carinho e paciência, associando-o à afetividade própria do estar-com humano. A análise compreensiva revelou, portanto, que o cuidado de enfermagem funda-se na disposição humana do cuidado, igualmente, ora comprometido e mediatizado pela razăo, com preocupação e solicitude, ora descansando na mera ocupação inautêntica própria do imediatismo mundano. Por fim, o estudo contribui para a consolidação da importância de investigações de fundamentação compreensivofilosófica com vistas à melhoria da qualidade do cuidado de enfermagem.
\end{abstract}

PALAVRAS-CHAVE: cuidado de enfermagem, fenomenologia, conceito

\section{INTRODUÇÃO}

O objetivo do trabalho da enfermagem é o "cuidado", premissa que tem sido aceita pelos profissionais. Deste modo, quando se define Enfermagem, diz-se que ela é a ciência e a arte do cuidado.

No entanto, sabe-se que o ato de cuidar é próprio da natureza humana, de modo que todo ser humano é capaz de cuidar de si e do outro. Considerando-se, portanto que todos são

'Estudo desenvolvido no Projeto Integrado de Pesquisa/CNPq: "Cuidado de Enfermagem: caminho para prevenir e reabilitar", como levantamento inicial para tese de doutorado em desenvolvimento junto ao Programa de Pós-Graduação em Enfermagem da Universidade Federal do Ceará (UFC).

${ }^{2}$ Doutoranda em Enfermagem da UFC. Professora da Universidade Estadual do Ceará (UECE). Enfermeira do Hospital de Messejana. Bolsista da Fundação Cearense de Desenvolvimento Cientifico e Tecnológico (FUNCAP).

${ }^{3}$ Doutora em Enfermagem. Professora da UFC. Pesquisadora do CNPq.

4 Alunas do Curso de Graduação em Enfermagem da UFC. Bolsistas PIBIC/UFC. 
cuidadores, os enfermeiros têm empreendido esforços no sentido de conceituar o que caracteriza o cuidado como próprio da Enfermagem.

A análise da trajetória desta profissão permite considerar que o cuidado, por certo, é leitmotio da ação do enfermeiro. Geovanini (1995) lembra que a prática de cuidar na Enfermagem nasceu como intuição feminina no seio familiar para depois caminhar na direção de tornar-se uma ciência humanizada, respaldada, inicialmente, no conhecimento de outras ciências para, mais recentemente, procurar fundamentação em teorias próprias, ao que se denomina Enfermagem moderna.

Tal modernização surgiu com Florence Nightingale, uma inglesa que, como enfermeira, trabalhou na Guerra da Criméia, na década de 50 do século XIX, quando desenvolveu um modelo de atenção em enfermagem, revolucionário àquela época, pois que, diante do desconhecimento da microbiologia, já havia preocupação com fatores ambientais e rigor higiênico (BECH; BUDÓ; GONZALES, 1998).

Desde então, os profissionais, influenciados pelo pensamento nightingaleano, passaram a procurar cientificização de Enfermagem, inicialmente, buscando o rigor dos procedimentos técnicos, influenciados pela tecnologia e pelo modelo biomédico de saúde. Tal rigor tecnológico avançou nos meados do século XX para a necessidade de ancorar a realização destes procedimentos em principios de outras ciências, principalmente as ciências da natureza.

Entretanto, a partir das décadas de 1960 e 1970, observa-se a preocupação dos enfermeiros, especialmente os norte-americanos, no sentido de descrever os fundamentos próprios da Enfermagem. Surgem então, as Teorias de Enfermagem, que, com base filosófica, tentam explicar os mais diversos fenômenos que permeiam o cuidado na profissão.

Em grande parte, os modelos teóricos consideram o cuidado como o foco principal da profissão e descrevem nuanças desta prática, tais como, o cuidado transcendental em Jean Watson, o cultural em Madeleine Leininiger, aquele para a adaptação em Calista Roy, dentre outros (GEORGE, 2000).

Porém, como registrado, o cuidado, como essencial da existência humana, não é próprio ou privativo de nenhuma prática profissional, por isso, de acordo com Lunardi Filho (1997), para caracterizar-se como cuidado de enfermagem, é necessária a apropriação do cuidado humano nato, só que, desta vez, imbuído de intencionalidade.

Deste modo, mesmo diante do que já se estudou e descreveu acerca do cuidado de enfermagem, autores como Waldow $(1997,1998,2001)$ têm chamado a atenção para a necessidade da realização de mais investigação acerca desta temática. Dentre os estudos já realizados, percebe-se com clareza uma lacuna no que tange a estudos que envolvam a compreensão dos conceitos utilizados na prática de enfermagem, sobremaneira, quando se trata do cuidado.

Donzelli (1997) chama a atenção para a necessidade de os enfermeiros voltarem-se para a "compreensão" e não meramente para a "explicação" dos conceitos que guiam sua prática profissional. Para tal afirmação, a pensadora transmite ensinamento de Martin Heidegger, filósofo alemão, ao dizer que a limitação dos conceitos correntes não permite que se atinja sua compreensão ou sentido originário. Revelar o que se encobre na mera aparência é alcançar o sentido, mostrando sua essência.

Com efeito, o presente estudo se volta para a interpretação do significado do cuidado de enfermagem, conforme expresso por enfermeiros e por pacientes por eles cuidados, com vistas a contribuir para a consolidação do conceito de cuidado como essencial na ação profissional.

Considerando os mais variados cenários nos quais o cuidado de enfermagem é vivenciado nas diversas situações que envolvem o binômio saúde-doença, este estudo voltou-se para a situação de cuidar em unidade de internação do tipo clinica médica. O cuidado constitui área de grande prevalência de internações hospitalares de pessoas adultas. 
Cuidado de enfermagem: o sentido...

\section{OBJETIVOS}

- Compreender o conceito de cuidado de enfermagem, a partir do discurso dos enfermeiros que desempenham atividades em clinica médica.

- Conhecer como os pacientes interpretam o cuidado de enfermagem a eles dispensado.

\section{METODOLOGIA}

O objeto de estudo desta investigação é de cunho compreensivo, portanto, configura-se como uma obscuridade que requer análise qualitativa para sua explicitação. Para Polit e Hungler (1995), nas pesquisas qualitativas, são coletados e analisados dados pouco estruturados e narrativos que proporcionam campo de compreensão das percepçöes e subjetividade dos seres humanos.

Portanto, trata-se de uma investigaçäo descritiva, com fundamentaçăo filosófica no pensamento de Heidegger (1993a; b), pensador que estudou as caracteristicas existenciais do ser humano e que compreende o cuidado como a mais originária.

O locus da pesquisa foi um hospital de ensino localizado na cidade de Fortaleza-CE. Tomou-se como sujeitos os enfermeiros que dispensam cuidados na Unidade de Clinica Médica daquela instituição de saúde ( 14 no total) e 15 pacientes ali internados no mês de janeiro de 2001 (periodo estabelecido para a coleta dos dados), que se encontravam em condiçōes clínicas de ser entrevistados e, quando convidados, aceitaram participar do estudo.

Utilizou-se, como forma de obter as informações, dois instrumentos para cada grupo amostral, quais sejam, formulários que serviram de meio para obter dados que permitiram a caracterização das populações amostrais e um roteiro de entrevista que permitiu buscar o objeto da investigação. A questão utilizada para introduzir e nortear as entrevistas de profissionais e pacientes foi: $O$ que é para você o cuidado de enfermagem?

Registre-se que todo o processo de coleta de informações seguiu os trâmites éticolegais de uma pesquisa cientifica, tal como preconiza a Portaria 196/96, do Conselho Nacional de Saúde, como aprovação do projeto de pesquisa em Comitê de Ética, garantia de anonimato da instituição e dos sujeitos participantes do estudo na apresentação dos resultados da pesquisa, entre outros.

Como era fundamental a obtenção, na integra, dos discursos dos enfermeiros e pacientes, após convite e aceitação para a participação no estudo, utilizou-se o recurso da gravação das entrevistas em fita cassete. A eles também foi garantido, conforme sugere a legislação, o direito de solicitar afastamento da pesquisa, se assim lhes aprouvesse. Para assegurar tais privilégios, foi assinado pelos participantes, o Termo de Consentimento Pós-Informaçăo.

$\mathrm{Na}$ apresentação e discussão dos dados, como meio de preservar a não-identificação dos sujeitos, enfermeiros e pacientes estäo registrados, respectivamente, pelas letras " $E$ " e "P", seguidas de numerais.

De posse das informações, foi procedida a tabulação manual dos dados de identificação dos grupos participantes. O conteúdo procedente das entrevistas foi submetido a análise de discurso, conforme ensina Fiorin (1997). De acordo com o autor, o discurso possui percurso gerativo de sentido, seja narrativo ou discursivo. Do narrativo, entende-se a descrição abstrata de algo pelas significações do narrador e o nivel discursivo oferece abstração da dimensão narrativa.

Assim, o discurso é uma combinação de elementos lingüisticos usados por quem fala para expressar pensamentos e agir. Para alcançar o sentido ou compreensão do discurso, este deve ser entendido como figurativo e temático. Para o alcance da compreensão do discurso figurativo, é necessário apreender o tema que nele se encobre.

Para fundamentar a compreensão dos discursos de enfermeiros e pacientes participantes 
deste estudo, utilizou-se, como registrado, o ensinamento filosófico de Heidegger, em sua obra primordial Sere Tempo (1993 a; b).

\section{O QUE SE REVELOU}

\section{Os Participantes do Estudo}

Dos 14 enfermeiros que participaram deste estudo, 13 são mulheres. Sua idade variou entre 25 e 45 anos, com média de 32,5 anos. Deles, 8 são casados, 5 solteiros e 1 divorciado. O tempo de formado oscilou de 2 a 22 anos, com média de 8 anos. A experiência profissional destes enfermeiros concentrou-se, essencialmente, em ambiente hospitalar, embora tenham sido encontrados áreas de ensino (4), ambulatório (4) e Programa de Saúde da Família (2). A carga horária de trabalho concentrou-se entre 30 a 50 horas/semanais.

Os enfermeiros participantes do estudado têm preocupação de continuar seus estudos em cursos de pós-graduação, sendo que 10 deles realizaram cursos de especialização, inclusive mais de um tipo. O curso mais procurado é Enfermagem Médico-Cirúrgica (7). Deles, 3 estão cursando especialização em Enfermagem em Cardiologia (2) e Gerontologia (1). Os enfermeiros também procuram participar de eventos cientificos, como os congressos da categoria. Quanto à produção de trabalhos cientificos, 11 deles referiram as monografias dos cursos lato-sensue 7 disseram ter realizado outras pesquisas.

Quanto aos pacientes, a idade variou de 16 a 50 anos, com média de 32,8 anos. Eles são do sexo masculino (8) e feminino (7). Quanto à escolaridade, 8 possuem ensino fundamental; 6 , o ensino médio; e 1 não possui instrução formal. A renda familiar referida foi de $R \$ 300,00$ a $\mathrm{R} \$ 1.000 .00$ (10), sem renda (2), não souberam informar (2) e entre $\mathrm{R} \$ 1.000,00$ a $R \$ 1.500,00$ (1).

Dos pacientes, 13 são oriundos de vários municipios do Estado, 1 de Fortaleza e 1 de outro Estado. Deles, 12 disseram saber distingüir os enfermeiros e as auxiliares de enfermagem.

Eles estavam internados por doenças cardiovasculares (6), renais (4), gastrintestinais (2), neurológica (2) e auto-imune (1). O tempo de diagnóstico médico variou de 10 dias a 20 anos, com média de 4,2 anos. O número de internações variou de 1 a 5 vezes, com média de 2,1. O tempo de internação atual variou de 5 a 30 dias, com média de 12,2.

\section{Os Discursos}

Conforme referido, foram apreendidas nos discursos dos participantes do estudo figurações lingüisticas que levaram a temas propicios à interpretação de suas falas.

Os enfermeiros expressaram figurações lingüistica, nas quais se evidenciou como tema:

o cuidado de enfermagem prende-se à satisfação das necessidades dos pacientes, com vistas ao seu bem-estar físico e emocional.

Quando Ihes foi indagado o que compreendiam por cuidado de enfermagem, seu discurso revelou que esta prática assim é configurada:

É promover o bem estar do paciente (...) Também é você orientar o paciente quanto a importância do tratamento (...) Ao paciente acamado é dado maior assistência. E1

É tudo que a gente faz para satisfazer as necessidades humanas básicas do paciente (...) desde o banho no leito até a orientação para a saúde (...) para que ele volte a ter uma vida normal. E2

É o cuidado que enfermeiro, técnico ou auxiliar de enfermagem prestam em cima das 
necessidades apresentadas pelo paciente (...) não só no plano físico, mas no emocional e (...) espiritual. E3

Envolve toda aquela coisa do enfermeiro pensar, planejar a assistência que vai prestar.E4

Em primeiro lugar é o bem-estar do paciente (...) é você não ver a doença e sim o paciente, vê-lo saindo com saúde. E5

Eu acredito que seja a assistência que a gente dá ao paciente (...) não só a parte fisica (...) mas vê a pessoa em si (...) olhar o paciente (...) principalmente aqueles graves. E6

É você assistir o paciente de acordo com sua necessidade (...) fazer por ele o que ele não pode fazer por si mesmo (...) para o se bem-estar. E7

Resolver coisas que estão Ihe incomodando. E8

Cuidar do paciente como um todo (...) tanto o lado psicológico quanto o fisico. E9

Ajudá-lo a tornar-se independente, fazer o eu ele não pode fazer sozinho. E10

É todo o trabalho dispensado ao paciente da clínica (...) seja o trabalho manual em si (...) seja o lado social (...) mais cuidado com os pacientes mais graves. E11

Assistir o paciente como um todo, não só vendo a parte física, tentando vê-lo como um todo (...) satisfazendo suas necessidades. E12

Atendendo as necessidades do paciente (...) com aquele grave você cuida mais direto.E13

É você vê o paciente como ser humano (...) que está precisando de sua ajuda. E14

Diante destas figurações narrativas, pode-se considerar que os enfermeiros associam o cuidado de enfermagem à satisfação das necessidades do paciente e à promoção de seu bemestar.

A terminologia empregada para tanto tem vinculaçăo com a Teoria das Necessidades Humanas Básicas, de Horta (1979). Esta teoria foi a primeira a ser divulgada no Brasil, tem sido muito utilizada no ensino, especialmente de graduação, em todo o Pais.

Quando se referem à satisfação das necessidades dos pacientes cuidados e à promoção do seu bem-estar, os enfermeiros relatam situações que dizem respeito a aspectos técnicos e atenção emocional e espiritual. Tal comportamento encontra apoio na Teoria Transpessoal, de Watson (1999), que considera o cuidado como uma relação em que enfermeiro e paciente estabelecem uma transação pessoal sublime.

O cuidado foi configurado também como o fornecimento de orientação que contempla o processo de educação em saúde.

A expressão de cuidado do E4 refere o planejamento sistematizado das intervenções. Tal referência encontra fundamento no processo de enfermagem. Segundo lyer, Taptich e Bemocchi-Losey (1993), para cuidar, o enfermeiro percorre, sistematicamente, 5 fases, conforme o modelo cientifico de pesquisa, quais sejam: levantamento de dados, diagnóstico de enfermagem, planejamento, intervenção e avaliação. Tal processo de raciocinio lógico permite ao profissional, de acordo com as autoras, prestar cuidado de enfermagem, com base cientifica.

A prioridade que os enfermeiros relatam oferecer aos pacientes graves (E1, E6, E11, 
E13) encontra apoio na Lei do Exercicio Profissional vigente (COFEn, 1986), que traz como atividades privativas deste profissional a execução dos procedimentos técnicos mais sofisticados e invasivos. Estes são, freqüentemente, renomeado nos pacientes internados nestas condições. Nesta direção, a execução dos procedimentos técnicos figurou-se na fala dos enfermeiros de modo a se tematizar que o cuidado de enfermagem prende-se à instância técnica. Os discursos assim revelam:

Eu cuido na administração de medicamentos (...) no banho no leito (...) na mudança de decúbito. E1

Cuidar é fazer alguma coisa que venha a beneficiar o paciente, seja providenciando exames (...) durante um banho (...) na prevenção de úlcera de decúbito. E3

Identificar a necessidade de cada um, fazer glicemia (...) mudança de decúbito (...) trocar escalpe. E6

Fazer todos os procedimentos com ele (...) fazer o curativo (...) dar o banho. E9

Fazer os procedimentos como colocação de sonda, remoção de curativos. E10

Principalmente nos graves, me concentro no banho, nos aparelhos que ele está monitorizando (...) no respirador (...) você acaba fazendo tudo maquinalmente. E11

De acordo com Nunes (1999), os profissionais enfermeiros, em geral, apresentam-se enfeitiçadas pelo poder que, aparentemente, a tecnologia Ihes concede. Deste modo, muitas vezes sua prática se direciona essencialmente para o exercício técnico, distanciando-se, portanto, dos valores morais e políticos imbuidos no cotidiano de trabalho. Nesta direção, Barnard (1997) lembra que, agindo assim, os enfermeiros se afastam da análise critica de sua realidade e mantêm-se na neutralidade rotineira de execução de procedimentos.

O discurso dos enfermeiros investigados nesta pesquisa figurou-se na associação do cuidado de enfermagem à realização de procedimentos. Portanto, consolida-se o pensamento dos autores referidos, porquanto os profissionais demonstram compreender o cuidado como administração de medicamentos, realização de banho no leito, de curativos, instalação de sondas, dentre outros procedimentos. Parece, pois, que a execução destas técnicas corresponde à sua ação cotidiana normal de prestar cuidado.

Entretanto, a despeito do fascínio em relação aos procedimentos técnicos, os enfermeiros também configuram seu cuidado profissional na instância existencial de modo a se tematizar que o cuidado de enfermagem é permeado pela relação interpessoal estabelecida entre enfermeiro e paciente. Dos seus relatos, apreendeu-se:

O cuidado acontece quando estou perto do paciente (...) me relacionando, conversando, orientando, ouvindo. E3

Cuidar é estar com o paciente (...) o paciente vem amedrontado e quando encontra uma equipe de enfermagem boa, ele começa a gostar do hospital (...) Conversar com ele (...) noto um sorriso (...) é recíproco, eu falo e o paciente também. E5

É estar ao lado do paciente (...) estar próximo e tentar ajudar até a resolver seu problemas pessoais. E8

O cuidado acontece em todos os momentos, quando eu chego, vou conversar com eles 
Cuidado de enfermagem: o sentido...

(pacientes). E9

Só em estar perto do paciente, conversando com ele, já me sinto cuidando, só em estar perto dele, ouvindo o que ele tem a dizer (...) isto para mim é cuidar. E10

Acho que cuido também no momento que eu converso com ele. E13

O cuidado de enfermagem para mim está muito além da parte técnica, é a humanização (...) você está diante de um ser humano precisando de sua ajuda (...) ter amor ao próximo, fazer uma caridade (...) com amor. E14

A conversa e a escuta da pessoa cuidada foram ações que os enfermeiros figuraram como cuidado de enfermagem. O diálogo entre enfermeiro e paciente é teorizado por Paterson e Zderad (1988) como o diálogo vivido. Na concepção das teóricas, para o cuidado humanizado, o diálogo é imprescindivel. Para que este ocorra, há de se estabelecer entre estes dois seres o encontro, a relação, a presença e o chamado-resposta. O encontro se dá no momento em que enfermeiro e paciente se aproximam nas situações de cuidado. Neste momento, estes seres, necessariamente, estabelecem relação interpessoal que se dá quando ambos têm disposição para estar-com-o-outro, caracterizando a presença. Enfim, o diálogo se estabeleceu no chamadoresposta que se dá na interlocução do cuidador e do ser cuidado.

Enfim, o cuidado de enfermagem requer a compreensão de que isto se dá na dimensão interpessoal e no diálogo. No entanto, esta prática deve ser assumida e não meramente ser mantida internalizada entre alguns profissionais (MORSE et al., 1991).

No que se refere ao discurso dos pacientes entrevistados, foi possivel descobrir figuração de sua linguagem que conduziu à tematização interpretativa. Para os pacientes, o cuidado de enfermagem configura-se como manifestaçōes de atuação, carinho e paciência, comportamento próprio na afetividade que deve ocorrer quando as pessoas estão em interação. Eles assim expressaram:

É cuidar bem (...) estar perto, olhando, prestar atenção na gente. P1

É o carinho especial que elas têm conosco, sempre vir aqui (no leito), saber como nós estamos (...) sempre ajudando com palavras e também tirando dúvidas. P2

É dar carinho atenção especial (...) ter paciência com a gente. P3

É ter muito cuidado e carinho (...) ser bom com a gente. P4

É o cuidado com o paciente, o carinho. P5

É tratar a gente (pacientes) com a maior educação do mundo (...) ajudar a resolver algum problema (...) escutar (...) acreditar no que a gente diz. Ter mais atenção com a gente.P6

É cuidar para o paciente ficar bom. A enfermeira tem que ser boa, paciente e atenciosa (...) passar sempre no quarto, conversar e saber como a gente está. P8

É a enfermeira ser atenciosa. P9

É ter preocupação com o paciente, tratar o paciente com carisma, carinho e amor especial (...) A enfermeira tem aquele nivel superior para tratar a gente, é formada para cuidar, tem que ter carisma. P10 
O cuidado é a enfermeira passar para perguntar se o paciente está precisando de alguma coisa. P12

É quando cuida bem, faz as coisas (os procedimentos) devagarinho (...) atende as pessoas bem (...) ter paciência (...) dar atenção. P13

É tratar bem (...) cuidar de saúde e tratar como ser humano. P14

É compreensão e responsabilidade (...) é ter muito amor com os doentes (...) dar carinho (...) dar de tudo pelo paciente (...) não se aborrecer quando o doente chamar, estar sempre atenta e não tratar mal. P15

Registre-se que, embora se tenha um profissional do sexo masculino compondo o grupo de enfermeiros daquele setor e, conseqüentemente, fazendo parte deste estudo, os pacientes sempre se referem à "enfermeira", em razão do grande contingente de mulheres nas equipes de enfermagem .

O estudo produzido por Waldow (1998), realizado com o intuito de relacionar os elementos para o cuidar e o cuidado na perspectiva de pacientes hospitalizados, tal como nesta investigação, em unidade de clinica médica, revelou que aquelas pessoas valorizam as dimensões existenciais no processo de ser cuidado. Quando relatam sobre os atributos necessários ao cuidador, eles requerem atitudes como paciência, atenção e carinho. Estas categorias foram igualmente lembradas pelos sujeitos da presente pesquisa. Quando indagados acerca da sua compreensão sobre o cuidado de enfermagem, seus discursos apontaram para a demonstração de atenção e preocupação.

Carinho, paciência e educação, igualmente, foram expressos pelos participantes do estudo como manifestações do cuidado. Eles esperam, portanto, que o cuidador tenha disposição para atendê-lo e que o faça de modo a considerá-lo "como ser humano". Eles expressaram que esperam ser atendidos nas suas necessidades, sendo que, para isso, desejam que seus chamados sejam atendidos imediatamente após a solicitação.

O discurso dos pacientes entrevistados também voltou-se para a associação do cuidado às orientações que eles esperam receber dos profissionais, no sentido da aprendizagem para o bem viver; para a responsabilidade que eles desejam ver demonstrada pelos enfermeiros e pela amizade que esperam receber. É interessante mencionar que, no estudo realizado por Waldow (1998), os pacientes expressam o amor tanto como atributo para quem cuida, como também, manifestaram este sentimento pelo profissional, quando por eles são cuidados.

Na presente investigação, os pacientes configuram, com menos ênfase, o cuidado como o desenvolvimento de procedimentos técnicos. Eles disseram:

O cuidado são os medicamentos. P1

É dar remédios, soro, injeção. P3

É o cuidado higiênico, físico, dar todas as informações. P9

É ter boa vontade, porque não é só dar injeção e fazer curativo, é o modo de como a pessoa chega com carinho, transmitindo confiança, que faz o doente acreditar que vai se recuperar, num ambiente amigo. P15

Deste modo, é importante considerar que, mesmo quando eles se referem aos cuidados instrumentais, também conferem atributos como carinho, atenção e responsabilidade ao cuidado 
prestado e, acima de tudo, a consideração pela pessoa cuidada. Tal relevância não se encontra na análise dos discursos dos profissionais.

\section{O SENTIDO DO CUIDADO PARA ENFERMEIROS E PACIENTES}

Buscar o sentido, velado por trás da mera aparência, significa, na fenomenologia heideggeliana, a tentativa de aproximação ao fundante, originário do fenômeno que lhe apresente. Nisto se dá a compreensão, correspondendo à apreensão do sentido, que se revela somente quando se deixa mostrar de onde, o que apenas é possivel alcançar pela mediação propiciada pelo uso da razão.

Tal sentido somente é possivel de apreensão quando se revela aquilo que se esconde no que é aparente. Portanto, é necessário mediatizar, pela razão, na tentativa de buscar-se o "eidos" ou essência do fenômeno pela epoché.

Diante do que se expressaram enfermeiros de clinica médica e pacientes por eles cuidados que participaram deste estudo, foi necessário que se dissecasse esta revelação, na tentativa de revelar o sentido que eles deram à sua linguagem.

Ora, enfermeiros e pacientes vivem no cotidiano de cuidado, habitando o chamado mundo do cuidar, descrito por Crossetti (1997), onde, segundo a estudiosa, ocorre relação interpessoal de seres cuidador e cuidado.

Neste estudo, foi apreendido do discurso de enfermeiros e pacientes do mundo do cuidar, em uma unidade de clinica médica, que o cuidado de enfermagem se funda na disposiçāo humana do cuidado, ora comprometido e mediatizado pela razão, com preocupação e solicitude, ora descansando na mera ocupação inautêntica própria da imediatez mundana.

Isto porque , em Heidegger (1993,a), a disposição humana é caracterizada pelo desejo de ser e estar com o outro no mundo e, dentre os modos da disposição está o cuidado como a mais própria das caracteristicas humanas. Para o Filósofo, o cuidado é zelo, desvelo e preocupação. No entanto, ele pode ser manifestado de dois modos, aquele denominado autêntico, no qual o cuidador considera compreensivamente o ser cuidado, ajudando a escolher suas possibilidades de existir. Tal comportamento autêntico ou originário se dá apenas quando o cuidador, não apenas se ocupa mundanamente com o outro, mas também se preocupa com ele, demonstrando-lhe solicitude.

Todavia, o cuidado também se manifesta de modo inautêntico, aquele que ocorre na grande parte das vezes, trata-se do momento em que o cuidador meramente se ocupa com o outro, sem no entanto, considerar seus desejos ou possibilidades de escolha. Isto acontece com mais facilidade, pois segundo o estudioso, é mais cômodo ao homem permanecer no mundo cotidiano na existência inautêntica na qual tudo é mediano e comum. A ninguém e a todos atribui-se a responsabilidade, de maneira tal, que todos são e ninguém propriamente é.

Diante destes ensinamentos, é possivel revelar que o cuidado de enfermagem, conforme aqui apreendido, é compreendido como manifestação autêntica, especialmente quando expressado pelos pacientes, embora oscile e descanse para a dimensão cotidiana e inautêntica da mera execução de procedimentos. Esta ambigüidade é revelada, principalmente, quando os enfermeiros, mesmo alicerçando o cuidado nas técnicas de enfermagem, consideram as relações interpessoais com os seres cuidados e à disposição de devolver-lhes bem-estar.

\section{CONSIDERAÇÕES FINAIS}

A presente investigação teve a intenção de viabilizar o desvelamento da dimensão compreensiva do conceito do cuidado de enfermagem, tanto no discurso daquele que cuida - o enfermeiro, quanto daquele que é cuidado - o paciente. Mesmo diante da consciência de que uma investigação desta natureza não se presta à obtenção de resultados conclusivos, espera-se ter contribuido para o aclaramento deste importante construto da ciência da Enfermagem. 
Aqui está revelada a importância de o enfermeiro pensar e dispensar cuidados aos seus seres cuidados mediados pela preocupação e desvelo pelo outro, considerando este momento de comunhão que se dá entre aquele que, cientifica e humanamente, aprendeu os meios de ajudar o outro nas suas necessidades de saúde e de doença, e o outro que necessite receber tais cuidados.

Por fim, o estudo possibilita consolidar a importância e a contribuição que as investigações com caracteristicas qualitativas do tipo compreensivo-filosóficas possam trazer à melhoria da qualidade do cuidado de enfermagem, pois, uma vez desveladas estas nuanças, muito pode ser pensado e melhorado na prática do cuidar.

ABSTRACT: The objective of this research is to clarify the concept of nursing care through the analysis of the discourse of nurses and patients. The data were collected in a clinic of a university hospital in Fortaleza-Ceará, in January 2001. The sampling frame was categorized through forms, and the speech of nurses and patients was obtained through semi-structured interviews. Data were formatted into textual form and analyzed according to the discourse analysis method. In the following phase, results were interpreted based on hermeneutic principles. Results showed that nursing professionals link the concept of care to the satisfaction of patients' needs and to their physical and emotional wellbeing. However, even though, these professionals value the interpersonal relationship they establish with their patients, their main concern is technical. Patients, on the other hand, link nursing care to the manifestation of attention, affection and patience. The hermeneutic analysis revealed that nursing care is based on a human predisposition for assistance. This assistance can either be committed and conscious, when it is concerned and solicitous, or uncompromising when it is an inauthentic occupation which only meets mundane immediatisms. We concluded that this study promotes the consolidation of comprehensive-philosophical investigations which can contribute to the qualification of the nursing care.

KEYWORDS: nursing care, phenomenology, concept

RESUMEN: La investigación se desarrolló para saber qué concepto de cuidado se tiene en enfermeria a partir del discurso de enfermeros y pacientes. La recogida de los datos se hizo en enero de 2001, en la clínica médica de un hospital universitario en Fortaleza-CE. Para tal se utilizaron formularios para caracterizar las poblaciones del muestreo y también entrevistas semiestructuradas para obtener dichos discursos. Los datos se trabajaron descriptivamente mediante el análisis del discurso y, después, se sometieron a la interpretación hermenéutica. Aparte de saber que para los profesionales el cuidado está muy relacionado a la satisfacción de las necesidades de los pacientes el análisis comprensivo reveló que el cuidar se funda en la disposición humana del cuidado, comprometido y mediatizado por la razón. Por fin, el estudio contribuye para consolidar la importancia de las investigaciones con fundamentación comprensivo-filosófica con vistas a la mejoria de la calidad del cuidado en enfermeria.

PALABRAS CLAVE: cuidado de enfermeria, fenomenologia, concepto

\section{REFERÊNCIAS BIBLIOGRÁFICAS}

BARNARD, A. A Critical review of the belief that technology is a neutral object and nurses are its master. Ant. J. Ad. Nur., v. 6, n. 1, p. 126-131, 1997.

BECK, C. L. C. BUDÓ M. L. D.; GONZALES, R. M. B. O Cuidado na enfermagem - essência e possibilidade de crescimento para a profissão (cd-rom). ENFTEC, 6. 1998, São Paulo. Anais Eletrônicos 1cd-rom.

BRASIL. Conselho Federal de Eníermagem. Lei do Exercício Profissional de Enfermagem. Brasilia, 1986. 
Cuidado de enfermagem: o sentido...

CROSSETTI, M. G. O Processo de cuidar - uma aproximação à questão existencial na enfermagem. Florianópolis, 1997. 164 p. Tese (Doutorado em Enfermagem) - Departamento de Enfermagem UFSC.

DONZELLI, T. A. Método fenomenológico e a pesquisa em enfermagem. Curso proferido na Faculdade de Farmácia, Odontologia e Enfermagem da UFC, Fortaleza, 03-07 novembro, 1997.

FIORIN, J. L. Elementos de análise do discurso. 6. ed. São Paulo: Contexto, 1997.

GEOVANINI, T. Uma abordagem dialética da enfermagem. In: GEOVANINI, T. et al. História da Enfermagem - versões e interpretaçöes. Rio de Janeiro: RETIVER, 1995.

GEORGE, J. B. e col. Teorias de enfermagem - os fundamentos à prática profissional. Tradução: Ana Maria Vasconcellos Thorell. Porto Alegre: Artes Médicas, 2000.

HORTA, V. A. Processo de enfermagem. São Paulo: EPU, 1979.

HEIDEGGER, M. Ser e tempo. Tradução: Márcia de Sá Cavalcante. 4. ed. Petrópolis: Vozes, 1993. pte. a.

HEIDEGGER, M. Ser e tempo. Tradução: Márcia de Sá Cavalcante. 4. ed. Petrópolis: Vozes, 1993. pte. b.

IYER, P. W.; TAPTICH, B. J.; BERNOCCHI-LOSEY, D. Processo e diagnóstico em de enfermagem. Porto Alegre: Artes Médicas, 1993.

LUNARDI FILHO, W. D. A Prescrição computadorizada de cuidados de enfermagem - o planejamento como forma inovadora de facilitação do cuidado individualizado e de sua continuidade. Cogitare Enferm. Curitiba, v. 2, n. 1, p. 90-95, jan./jun. 1997.

MORSE, J. M. et al. Comparative analysis of conceptualizations and theories of caring. Image, n. 23, v. 2, p. 19-26, Summer, 1991.

NUNES, W. A. Do cuidar com tecnologia à tecnologia do cuidar. Ribeirão Preto, 1999. Tese (Doutorado em Enfermagem) - Escola de Enfermagem de Ribeirão Preto, USP.

PATERSON, J. G.; ZDERAD, L. T. Humanistic nursing. New York: National League for Nursing, 1988.

POLIT, D. F.; HUNGLER, B. P. Fundamentos de pesquisa em enfermagem. Porto Alegre: Artes Médicas, 1995.

WALDOW, V. R. Cuidado humano e a enfermagem: ampliando sua interpretação. Esc. Anna Nery R. Enferm. Rio de Janeiro, v. 1, n. 2, p. 142-153, dez. 1997.

Cuidado humano: o resgate necessário. Porto Alegre: Sagra Luzzato, 1998.

Peculiaridades e contradições do cuidar: um estudo etnográfico. Nursing, v. 33, ano 4, p. 1824, fev. 2001.

WATSON, J. Nursing - human science and human care - a theory of nursing. New York: National League for Nursing, 1999.

Recebido em agosto de 2001

Aprovado em dezembro de 2001 